\title{
PENANAMAN KONSEP TRI KAYA PARISUDHA DALAM TRADISI MARERAOSAN
}

\author{
Oleh: \\ Gek Diah Desi Sentana, SS., M.Hum \\ gekdiahdesisentana@gmail.com \\ Institut Hindu Dharma Negeri Denpasar
}

\begin{abstract}
ABSTRAK
Tradisi di Bali baik itu lisan dan tertulis selalu diusahakan terjaga kelestariannya, bukan hanya oleh masyarakatnya yang mayoritas beragama Hindu, tetapi juga oleh pemerintah. Hal itu dilakukan karena tradisi itu sendiri sebagian besar berkaitan dengan upacara yang dilakukan oleh umat Hindu Bali, dan sudah menjadi ikon masyarakat Bali. Sebuah tradisi akan selalu dapat berkembang dan eksis apabila didukung oleh pendukungnya itu sendiri, artinya selalu ada orang yang mau melestarikan tradisi tersebut, setidaknya dapat memperkenalkannya pada kalangan anak-anak sampai pada yang dewasa. Salah satu tradisi lisan yang menjadi bagian dari kearifan lokal daerah dan terdapat hampir di seluruh wilayah Bali yaitu tradisi yang berkaitan dengan ritual perkawinan yaitu tradisi mareraosan. Keterjalinan hubungan perkawinan antara mempelai dan keluarga didasari dengan perkawinan yang sah, legal dan telah mengikuti berbagai kegitan ritual perkawinan. Hampir seluruh warga di Bali merupakan bagian dari pola hubungan keluarga dan perkawinan seperti ini. Sehingga proses sosialisasi untuk keluarga seperti ini dapat berjalan dengan lancar dan baik. Keluarga dengan tipe seperti inipun bisa dikatakan keluarga yang baik sebab dengan sah dan legalnya sebuah keluarga, maka proses sosialasasi dan penerapan fungsi serta peran mempelai dalam masyarakat dapat berjalan dengan baik. Untuk memahami pentingnya perkawinan bagi keluarga dan masyarakat maka calon mempelai perlu diberikan pemahaman mengenai pentingnya konsep Tri Kaya Parisudha dalam ajaran Agama Hindu melalui Tradisi Mareraosan.
\end{abstract}

Kata Kunci: Tri Kaya Parisudha, Tradisi Mareraosan

\section{Pendahuluan}

Makna yang terkandung dalam perkawinan itu adalah adanya ikatan lahir batin antara individu yang dinamakan pria (lelaki) dan individu yang dinamakan wanita sebagai suami istri. Jelas bahwa ikatan dalam perkawinan itu seorang pria dengan seorang wanita menjadi suami istri dengan melalui lembaga perkawianan. Perkawinan adalah ikatan lahir batin, artinya dalam perkawinan tersebut perlu adanya ikatan bagi keduanya-duanya. Dinamakan ikatan lahir karena merupakan ikatan yang menampak. Disebut pula ikatan formal, sesuai dengan peraturan-peraturan yang ada. Ikatan formal ini adalah nyata, baik yang mengikat dirinya (suami-istri), maupun bagi orang lain (masyarakat luas). Maka dari itu setiap perkawinan pada umumnya diinformasikan kepada khalayak agar khalayak memahami dan mengetahuinya. Cara memberikan infromasi kepada masyarakat dapat ditempuh dengan bermacam-macam, tergantung adat, budaya, kebiasaan, atau tergantung dari kemauan yang bersangkutan, misalnya dapat ditempuh dengan memasang iklan atau media lainnya.

Kematangan emosi dan pola pikiran seseorang akan membuat seseorang itu mampu mengembangkan sikap toleransi antara suami istri. Bersikap toleran artinya mengembangkan 
unsure saling: memberi dan menerima (take and give), menghargai, menolong, memerdekakan pasangannya. Sikap toleransi memberikan gambaran bahwa masing-masing pasutri harus siap dan sedia berkorban untuk kepentingan keluarga yang telah dibina. Memupuk sikap toleransi bukan perkara yang mudah; namun hal ini perlu untuk tetap diusahakan dan dilaksanakan, tentunya membutuhkan adanya saling pengertian dari kedua belah pihak. Tanpa adanya toleransi satu dengan yang lain, mustahil dua pribadi itu dapat bersatu secara baik. Oleh karena itu, pada umur perkawinan yang masih muda, sering terjadi gejolak, adanya gelombang dalam keluarga yang muda tersebut.

Tradisi mareraosan yang terdapat dalam serangkaian upacara pawiwahan atau perkawinan yaitu tradisi yang dilakukan pada saat pengantin pria mendatangi rumah pengantin wanita untuk meminta restu kepada orang tua mempelai wanita. Tradisi ini tidak hanya melibatkan keluarga saja, tetapi juga prajuru adat atau pemuka adat dari tempat dimana kedua mempelai berdomisili. Menurut para pemuka agama, tradisi mareraosan tersebut dikenal sejak jaman dahulu dimana saat itu Tradisi mareraosan dipakai sebagai simbol restu dari orang tua dan kesanggupan kedua mempelai untuk berumah tangga. Dalam pandangan filsafat (tattwa), restu orang tau dan masyarakat terhadap keberlangsungan pernikahan tersebut dapat mengantarkan kedua mempelai menuju kebahagiaan atau ketentraman. Semua itu tergantung pada niat baik kedua belah pihak. Sehingga dalam tradisi ini pendidikan Grahasta Asrama menjadi hal yang penting ditanamkan oleh orang tua dan dipahami oleh kedua mempelai yang nantinya disampaikan dalam bentuk tuturan melalui tradisi mareraosan.

\section{Pembahasan}

Pendidikan agama Hindu dibedakan atas dua bagian yaitu pendidikan agama
Hindu di luar sekolah, dan pendidikan agama Hindu di lingkungan sekolah. Sehubungan dengan hal itu pendidikan agama Hindu harus diupayakan agar terlaksana dengan baik berkesinambungan sehingga tercipta keharmonisan hidup di dalam individu umat itu sendiri, intern umat beragama, serta antar umat beragama dalam mewujudkan kedamaian hidup. Tentang pentingnya pendidikan agama Hindu tersebut dalam kitab Suci Rg Veda X.32.7, sebagai berikut:

Aksetravit ksetravidam hyaprat sa paiti

ksetravidanusistah

Etad van bhadram anusasanasyo ta sruti vindatyas njasinam.

Terjemahan

Orang yang tak mengenal suatu tempat bertanya kepada orang yang mengetahuinya. Ia meneruskan perjalanan, dibimbing oleh orang yang tahu. Inilah manfaat pendidikan. Ia menemukan jalan yang lurus.

1996 : 249)

(Titib,

Demikian pentingnya pendidikan dalam menjalankan kewajiban hidup di dunia. Mereka yang tidak berpendidikan tidak ada sesuatu yang berarti yang bisa dilakukan, malahan ia akan dilecehkan dan dijauhi oleh orang-orang sekitarnya. Usaha-usaha untuk mempelajari sastra agama adalah suatu yang utama di dalam mengamalkan ajaran agama, sehingga menjadi orang yang berguna di tengah masyarakat. Pendidikan tentang ajaran Agama Hindu juga diajarkan di Masyarakat, seperti halnya konsep Tri Kaya Parisudha yang ditanamkan pada saat Tradisi Mareraosan.

Berdasarkan uraian tersebut, tujuan dari pendidikan agama Hindu mulia dan komperhensif mencakup berbagai dimensi kehidupan yang menekankan nilai-nilai agama Hindu sebagai landasan untuk meningkatkan kerukunan dan kedamaian hidup atas dasar astiti bhakti kepada Ida Sang Hyang Widhi Wasa. Dalam usaha mencapai kebahagiaan lahir bhatin yang menjadi tujuan agama Hindu bisa diwujudkan melalui berbagai perbuatan kebijakan seperti tertuang dalam Catur Purusa Artha yaitu Dharma, Artha, Kama, dan Moksa. Dharma berarti kebenaran dan kebajikan, yang menuntun umat manusia untuk mencapai kebahagiaan dan keselamatan, sedangkan Artha adalah benda-benda yang dapat memenuhi atau memuaskan kebutuhan hidup manusia. Kama 
artinya nafsu, keinginan dan juga berarti kesenangan, sedangkan Moksa berarti kebahagiaan yang tertinggi atau kelepasan (Kajeng, 2000: 12). Memenuhi keinginan harus berdasarkan atas kebenaran yang menjadi pengendali dalam memenuhi tuntutan kama atas artha sebagaimana diisyaratkan di dalam Kitab Suci Sarasamuscaya sloka 12, berikut ini:

kamarthau lipsmanastu dharmamevaditaccaret. na hi dharmmahapetyarthah kamo vapi kadacana Yan paramarthanya, yan arthakama sadhnyam, dharma juga lekasakena

Rumuhun, niyata katewaning arthakama mene tan paramartha wi

katemwaning arthakama deninganasar sakeng dharma.

Terjemahan

ada hakekatnya, jika artha dan kama dituntut, maka seharusnya dharma hendaknya dilakukan terlebih dahulu. Tidak dapat disangsikan lagi, pasti akan diproleh artha dan kama itu nanti. Tidak aka nada artinya, jika artha dan kama diproleh menyimpang dari dharma (G.Pudja, 1985: 15).

Kutipan sloka tersebut di atas dapat diartikan bahwa karena dharmalah yang menuntut manusia untuk selalu berprilaku yang baik guna mendapatkan kebahagiaan yang sejati untuk mencapai kebahagiaan yang kekal dan abadi. Menurut Sasmika, upacara mareraosan ini memberikan pendidikan kepada masyarakat bahwa agama Hindu itu adalah Fleksibel atau praktis. Karena dalam menjalankan yadnya tidak diharuskan menggunakan sarana yang tingkatannya Utama dan Madya tetapi bisa juga dengan nista atau upakara yang paling sederhana. Dalam agama Hindu tidak ada unsur memaksakan tetapi dalam meninjukan rasa bhakti masrayarakat dianjurkan untuk menyesuaikan dengan kemampuan dalam beryadnya.

Dari pemaparan di atas maka dalam tradisi mareraosan memiliki pendidikan agama yang terakomodasi. Baik itu pendidikan agama non formal (di luar sekolah) maupun pendidikan agama yang informal dan formal sekalipun. Misalnya praktek mejejaitan dari mata pelajaran yadnya atau pada saat mendapatkan pelatihan di pasraman yang dilaksanakan oleh sekolah atau desa adat. Tradisi mareraosan memiliki fungsi pendidikannya berupa pendidikan non formal. Seperti pengetahuan tentang bentuk banten tradisi mareraosan, dan fungsi dari banten tradisi mareraosan dan juga mengajarkan kepada umat untuk beryadnya sesuai dengan kemapuan, karena agama Hindu adalah agama yang fleksibel dan praktis tidak ada unsur keterpaksaan dalam menghubungkan diri kehadapan Ida Sang Hyang Widhi Wasa.

Setiap agama yang ada di Indonesia mempunyai etika atau tata susila yang telah diyakini kebenarannya sebagai pedoman hidup di dalam kehidupan sehari-hari. Tata susila berarti peraturan tingkah laku yang baik dan mulia yang harus menjadi pedoman hidup manusia.Mantra (1989:5) menyebutkan tata susila merupakan peraturan tingkah laku untuk membina watak manusia menjadi baik dan mulia. Watak manusia yang baik dan mulia dapat dibina mulai dari kehidupan keluarga, masyarakat, dan sekolah sehingga menjadi manusia yang berpribadi baik dan diterima oleh lingkungannya. Manusia yang lahir di dunia untuk bisa diterima oleh lingkungannya, sesamanya serta dalam memuja Tuhan hendaknya selalu berusaha berbuat baik dan benar. Dalam kitab Sarasamuscaya sloka 2 diuraikan:

Manusa sarvabhutesu.

Varttete vai cubhachube

Acubehesu samawistam

cubheswawe wakarayet.

Terjemahannya

Dari demikian banyaknya semua mahluk yang hidup, yang dilahirkan sebagai manusia itu saja yang dapat berbuat baik burukitu; adapun untuk peleburan perbuatan buruk ke dalam perbuatan yang baik juga manfaatnya jadi manusia. (Pudja, 1986: 10-11)

Sloka itu mengingatkan kita sebagai mahluk ciptaan Tuhan yang paling utama, karena telah diberikan Tri Pramana yaitu bayu, sabda, dan idep. Ketiga kekuatan ini mendorong masyarakat Desa Adat Kwanji untuk melaksanakan upacara mareraosan atau beryadnya. Seperti dalam Bhagawadgita Bab III sloka IX diuraikan:

Yajnarthat karmano'nyatra

loko'yam karma bandhanan, tadartham karma kaunteya

mukta sangah samacara

Terjemahanya 
Dari tujuan berbuat yadnya itu menyebabkan dunia ini terikat oleh hukum

karma, karena itu, O Arjuna, bekerjalah tanpa pambrih, tanpa kepentingan pribadi, Oh Kuntiputra. (Swami Prabhupada, 1986: 171).

Berdasarkan sloka tersebut bahwa tujuan melaksanakan Tradisi mareraosan menyebabkan dunia ini terikat oleh hukum karma. Karena itu diharapkan bekerja tanpa mengharapkan hasil atau pambrih, bekerja yang giat dan pikiran menyatu pada Brahman. Dalam pengabdian diharapkan juga tidak berkata-kata kasar yang menyebabkan sakit hati bagi yang mendengarkannya.

Adapun bagian dari pendidikan susila yang terkadung dalam tradisi mareraosan jika dikaitkan dengan ajaran pendidikan susila maka termasuk dalam ajaran tri kaya parisudha, yang berarti tiga jenis tindakan yang merupakan landasan ajaran etika agama Hindu dalam menjalani atau memasuki masa grehasta asrama atau masa berumah tangga. Bagian dari Tri Kaya Parisudha yaitu yang terdiri dari manacika, wacika, kayika. Seperti yang diuraikan dalam Sarasamuscaya sloka 41 yaitu:

Kunang deyanta, hana ya prawrtti, kapuhara dening kaya, wak, manah, ndatan panukhe ya ri kita, magawe duhkha puhara hrdroga, yatika tan ulahakenanta ring len, haywa tan harimbawa ika gatinta mangkana, ya tika sangksepaning dharma ngarannya, wyatha kada melaning dharma yan mangkana, lilanta gawayakena ya.

\section{Terjemahannya}

Adapun yang harus engkau perhatikan, adalah hal yang ditimbulkan oleh perbuatan, perkataan, dan pikiran yang tidak menyenangkan dirimu sendiri, malahan menimbulkan kesusahan yang menyenangkan dirimu sendiri, malahan menimbulkan kesusahan yang menyebabkan sakit hati; yang demikian itu janganlah engkau lakukan kepada orang lain, jangan tidak mengukur baju dibadan sendiri, prilaku yang demikian itu, singkatnya itulah dharma namanya. Penyimpangan dalam melaksanakan dharma yang demikian hendaknya jangan dilakukan (Pudja, 1986: 29)

Berdasarkan sloka di atas bahwa Tradisi Mareraosan juga disampaikan bahwa dalam melaksanakan sesuatu kita seharusnya memperhatikan perbuatan, perkataan, dan pikiran, agar nantinya kita tidak mendapatkan kesusahan akibat kelakuan atau laksana kita sendiri terutama jika sudah memasuki masa Grahasta Asrama ( perkawinan). Landasan tri kaya parisudha dalam Tradisi Mareraosan sebagai berikut:

\section{Kayika Parisudha}

Kayika Parisudha adalah perbuatan atau laksana yang baik merupakan pengamalan dari pikiran dan perkataan yang baik. perbuatan yang baik dapat dilakukan dari adanya pengendalian pada tingkahlaku, utamanya pada himsa karma yaitu perbuatan menyakiti, menyiksa, atau membunuh mahluk yang tidak berdosa atau bersalah. Pedoman tata susila menuntun kita kearah menyatukan dan tidak memecah belah. Adapun yang dituntut adalah perasaan manusia kearah keselarasan antara sesama manusia dan mahluk hidup lainnya. Dalam kita bertingkah laku hendaknya selalu memikirkan apa yang akan terjadi nantinya atau dampak apa yang akan ditimbulkan, agar nantinya sesuai dengan apa yang kita inginkan atau selaras teman atau kawan. Agar tidak saling merugikan atau menimbulkan sakit hati terhadap seseorang. Perbuatan yang berpatokan pada dhrama, yang di peroleh dari kitab suci selalu akan membawa kita kepada kebebasan, kedamaian, dan kebahagiaan, kedepannya diharapkan kedua mempelai menjalankan masa berumah tangga dianugrahi kesenangan, kedamaian, kerahayuan, kebahagiaan dan mendapatkan anak yang suputra.

\section{Wacika Parisudha}

Perkataan yang baik, manis didengarkan oleh setiap orang. Perkataan itu patut timbul dari dalam hati yang tulus, lemah lembut penyampeannya dan menyenangkan hati pendengarnya. Untuk dapat berkata yang baik patut dipikirkan terlebih dahulu. Terlanjurnya berkata-kata akan sulit ditarik kembali. Kata-kata merupakan sarana komunikasi yang paling cepat diterima di dalam pergaulan, perhubungan, pendidikan, penyuluhan, penerangan dan sebagainya. Dalam Nitisastra sargah V dijelaskan:

Wasita nimittanta manemu laksmi, wasita nimittanta manemu kepangguh, wasita nimittanta manemu dukha, wasita nimittanta manemu mitra 
Terjemahannya

Oleh perkataan engkau akan mendapat kebahagiaan, oleh perkataan engkau akan mendapatkan kematian, oleh perkataan engkau akan mendapatkan kesusahan,

dan oleh perkataan engkau akan mendapatkan sahabat.

(Suhardana, 2008: 31).

Dari pernyataan sloka di atas dapat diartikan bahwa perkataan adalah yang paling penting harus dijaga karena lewat perkataan kita akan menemukan kebahagiaan, kematian, kesengsaraan, dan mendapatkan sahabat. Dalam berucap agar selalu memikirkan terlebih dahulu, dan juga kita harus memperhatikan siapa lawan bicara kita saat berkomunikasi agar nantinya tercipta keharmonisan terhadap sesama. Karena ucapan seperti harimau, jika kita bisa mengontrol dan memperhatikan di dalam kita berbicara maka akan mendapatkan kebahagiaan, jika kita tidak bisa mengontrol atau acuh, maka kita akan menemukan kesengsaraan.

Pada saat menyampaikan maksud untuk melaksanakan tradisi mareraosan kepada pihak mempelai wanita, Juru raos dan keluarga mempelai laki-laki hendaknya berbicara secara halus dan penyampaiannya yang manis agar nantinya maksud dan tujuan diterima dengan senang hati. Sehingga pengetahuan mengenai anggah ungguhing basa Bali sangat dibutuhkan demi keberlangsungan tradisi mareraosan.

Jadi didalam kita berkomunikasi hendaknya selalu berdasarkan etika dan juga menggunakan tata bahasa yang baik tanpa terbawa emosi perasaan karena tidak semua orang bisa menerima apa yang kita sampaikan, juga di dalam kita berkomunikasi terhadap orang kita harus memperhatikan apakah seseorang tersebut lebih tua dari kita apa tidak agar tidak terjadi ketersinggungan nantinya.

\section{Manacika Parisudha}

Manacika berarti perilaku yang berhubungan erat dengan pikiran. Manacika parisudha adalah berpikir yang benar dan suci. Diantra tri kaya parisudha ini, pikiranlah yang menentukan dan memegang perana. Apa saja yang ada dalam pikiran akan tercetus dalam kata-kata, dan terwujud pula dalam perbuatan. Pikiran adalah sumber segala apa yang dilakukan oleh seseorang. Dalam sarasamuscaya sloka 80 diuraikan:

Apan ikang manah ngaranya, ya ika witning indrriya, maprawrtti ta ya ring subhaasubhakarma, matangnya ikang manah juga prihen kahrtanya sakareng.

Terjemahanya

Sebab pikiran itu namanya adalah sumbernya indriya, ialah yang menggerakan perbuatan baik buruk itu, karena itu, pikiranlah yang patut segera diusahakan pengendaliannya.

Dari pernyataan sloka di atas maka dapat diartikan bahwa pikiran adalah sumber segalanya karena pikiran mampu menggerakan segala indria kita dalam kita melakukan sesuatu, maka usahakanlah pikiran harus dikendalikan karena dengan pikiran kita bisa merasakan kedamaian, dan dengan pikiran kita bisa merasakan kehancuran.

Sebagai pasangan suami istri, hendaknya kedua mempelai mampu mengendalikan pikiran, sebab pikiran itu seperti kuda liar jika tidak dikendalikan. Melaksanakan tradisi mareraosan harus didasari oleh hati yang tulus iklas, karena dengan ketulus iklasan semuanya akan berjalan dengan lancar sesuai dengan apa yang akan diharapkan.

Bertingkah laku yang baik bersumber dari pikiran yang baik maka dari itu sebelum berbuat atau berkata hendaknya berpikir terlebih dahulu dan menyesal belakangan tidak berguna, jika ada tingkah laku atau perbuatan yang kurang berkenan dihati. Mengenai pikiran diuraikan dalam kitab Sarasamusccaya sloka 79 seperti berikut:

Kunang sangksepannya, manah nimittaning niscaya jnana,dadi

pwang niscaya jnana, lumekas tang ujar,lemekas tang maprawrtti, matangnyan manah ngaranika pradhanan mangkana.

Terjemahannya

Adapun kesimpulannya, pikiranlah yang merupakan unsur yang menentukan; jika penentuan perasaan hati telah terjadi, maka mulailah orang berkata atau melakukan perbuatan. Oleh karena itu pikiranlah yang menjadi pokok sumbernya. (Pudja, 1986: 49). 
Tradisi mareraosan merupakan suatu tradisi yang perlu dilestarikan, sebab adat dapat juga mendidik masyarakat untuk dapat bertingkah laku yang baik dan benar. Dengan perbuatan yang baik akan menyebabkan seseorang dikenal oleh masyarakat luas, dengan melaksanakan tardisi mareraosan dikehendaki suatu keturunan yang mulia dan bertikah laku susila atau anak yang suputra. Karena setiap orang mendambakan sesuatu yang baik dan berguna bagi keluarga, masyarakat dan Negara. Dalam kitab Sarasamuccaya sloka 21 disebutkan:

Kunang ikang wwang gumaway ikang subhakarma, janmanyan

Sangke ring swarga delaha, litu hayu maguna, sujanma sugih,

mawarya, phalaning subhakarma wasana tinemunya.

Terjemahannya

Adapun orang berbuat baik, kelahirannya dari surge kelak menjelma menjadi orang yang rupawan, gunawan, muliawan, hartawan dan berkuasa pahala dari perbuatan baik yang diprolehnya. (Pudja, 1986: 19).

Berdasarkan sloka tersebut bahwa orang yang baik adalah kelahiran dari surga akan menjelma nantinya sebagai manusia yang rupawan, gunawan, muliawan, hartawan sehingga semua orang mendambakannya untuk dapat mengabdikan dirinya pada keluarga, masyarakat, dan Negara. Perbuatan yang baik dikehendaki dalam pelaksanaan tradisi mareraosan juga kesungguhan hati dan kesucian pikiran sehingga dicapai suatu kesabaran dalam menempuh hidup yang penuh kebahagiaan serta kebajikan, karena orang yang berbuat kebajikan akan berpahala juga. Karena semua peraturan yang telah disepakati bersama dan disampaikan di hadapan seluruh masyarakat yang hadir dalam tradisi mareraosan haruslah dilaksanakan secara turun temurun.

Segala sesuatu yang berhubungan dengan tingkah laku yang baik dan benar itu masih banyak ada untuk dapat member motivasi kearah yang baik yaitu yang diuraikan dalam Sarasmusccaya Sloka 74-76 yaitu: Prawwrttyaning manah rumuhun ajarakena, telu kwehnya, pratyekanya, si tan engine adengkya ri drbyaning len, si tan krodha, ring sarwa sattwa, si mamituhwa ri hana ning karmaphala, nahan tang tiga ulahning manah, kahrtaning indriya.

Terjemahannya

Sifat hakekatnya pikiran (manah) yang pertamatama akan diajarkan, tiga banyaknya, perinciannya, tidak menginginkan dan dengki terhadap milik orang lain, tidak marah kepada semua mahluk, percaya akan kebenaran ajaran karmaphala, itulah ketiga bentuk sifat pikiran sebagai pengendali terhadap (panca) indrinya itu. (74).

Nyang tanpa prawrttyaning wak, pat kwehnya, prattyekanya, ujar ahala, ujar aprgas, ujar picuna, ujar mithya, nahan tang pat sing gahananing wak, tan ujarakena, tan angenangen, kojaranya.

Terjemahanya

Inilah yang tidak patut timbul dari perkataan (wak), empat banyaknya, masing-masingnya, perkataan yang jahat, perkataan yang kasar menghardik, perkataan yang memfitnah, (dan) perkataan bohong, itulah keempat, supaya dijauhkan dari kata-kata itu, jangan diucapkan, pun juga tidak terpikir untuk diucapkan.(75).

Nihan yang tan ulahakena, syamatimati mangahalahala, si paradara, nahan tang telu tan ulahakena ring asing ring parihasa ring apatkala, ri pangipyan tuwi singgahana jugeka.

Terjemahannya

Inilah yang tidak patut kau lakukan, membunuh, mencuri, berzinah, ketiganya itu jangan hendaknya kau lakukan terhadap siapapun, baik secara berolokolok, bersenda gurau, dalam keadaan dirundung malang, bahkan dalam keadaan mimpipun hendaknya supaya dihindari ketiganyaitu. (Pudja, 1986: 46-48).

Berdasarkan sloka tersebut di atas bahwa sesuatu yang membawa akibat yang baik hendaknya dipupuk terus lebih-lebih tingkah laku berdasarkan Tri Kaya Parisudha. Tri Kaya Parisudha sebagai landasan pelaksanaanya.Tradisi mareraosan merupakan kewajiban yang diutamakan dan harus dilaksanakan sehingga mendapat anugrah dari Ida Sang Hyang Widhi Wasa suatu kebahagian di dunia dan di akhirat. 


\section{Penutup}

Ajaran-ajaran agama Hindu mengharapkan umatnya agar berbuat baik dan mulia. Agar terjadinya keselarasan antara hubungan seseorang dengan mahluk hidup disekitarnya. Karena itu perlu ada suatu aturan tertentu dalam bertingkahlaku, dalam hal ini lebih dikenal dengan tata susila. Hubungan yang selaras antara keluarga membentuk masyarakat, antara bangsa dengan bangsa lain antara manusia dengan alam sekitarnya. Terbinanya keselarasan hubungan mengakibatkat suatu kehidupan yang aman dan sentosa. Bila sebaliknya, akan mengakibatkan kehancuran, mala petaka akan menimpa. Maka diperlukan suatu kesadaran pribadi untuk berperilaku yang baik demi terpeliharanya tata susila, sebagai satu-satunya aturan prilaku yang mulia seperti yang telah digariskan melalui ajaran ajaran agama, khususnya agama Hindu.dengan dihayati dan diamalkan tata susila tersebut dengan sendirinya juga tergolong ikut menjaga ajaran agama tersebut (Mantra, 1997:5).

Tradisi mareraosan mengajarkan betapa pentingnya Tri Kaya Parisudha yaitu di dalam berbicara kepada orang tua tidak boleh sembarangan, terlebih lagi hubungan dengan masyarakat harus selalu dijaga dengan baik, dan yang terpenting selalu berfikir yang baik sehingga tercipta keharmonisan di dalamlingkungan keluarga dan masyarakat.

\section{DAFTAR PUSTAKA}

Koentjaraningrat. 1991. Metode-metode

Penelitian Masyarakat. Jakarta :Aksara Baru.

Nasikun. 2003. Sistem Sosial budaya Indonesia.

Jakarta : PT. Raja Grafindo Persada.

Rohman, Arif. 2009.Memahami Pendidikan

dan Ilmu Pendidikan. Yogyakarta: Laksbang

Media Tama.

Sugiyono. 2005. Metode Penelitian Pendidikan.

Bandung: Alfabeta.

Wiyatmi. 2005. Pengantar Kajian Sastra. Yogyakarta: Pustaka. 